\title{
The People's Attitude towards the Language Use in the Local Media Broadcast: A Case Study of Azerbaijani language in Tabriz
}

\author{
Asefeh Zeinalabedini \\ Australian National University, Australia
}

\section{Introduction}

The public broadcast media, to which the television (TV) and radio belong, are arguably the most significant but a controversial topic discussed in linguistic literature (Sherrington 1973; Weisse 1985; Madianou 2005; Lysaght 2009; Sheyholislami 2010).

The spread of information through public media engages a vast majority of people and certain communities in a meaningful dialogue, as well (Sherrington, 1975; Lysaght, 2009). Lysaght (2009) suggests that national television has a key role in exploring central beliefs and popular culture, such that the language used in broadcasting has huge symbolic importance. Public broadcasting is a significant form of information release in many countries. The broadcast media is not just a mechanical device for transferring information around the world, but is able to create a new language with new powers of expression. Fisk and Hartley (2003) note that this power of language is magnified by broadcast media. The public media can establish new values for many people either inside or outside of it (The National Center for Media Engagement, 2013). For instance, in an attempt to mobilize the public into action or to promote a change of attitude, programs are presented to reach both city and urban dwellers without sensitivity to the rules of the language used in public and private sectors. This degree of influence is intuitive, since the television and radio programs are largely oral and visual, with little or no opportunity provided for interaction with them. On the other hand, it is widely accepted that language occupies a prominent place in discussions of national identity (Lysaght 2009; Edwards 2009; Fishman 1989; Joseph 2004). Recently Lysaght (2009) in New Zealand, Jones (2007) in the UK and Hartley 
(2004) in Canada have shown the effectiveness of employing satellite television in the reconstruction of collective and national identities among people without a state of their own.

This study sets out to investigate people's attitudes towards the language that is used in the broadcast media, including local television and radio, and find out why people prefer to use or refuse a local media. We then set up a case study and focus on a specific area where the official language in public media broadcasting has a significant impact on the native language of that area.

We conduct our research on Azerbaijani language in Tabriz, which is one of the major cities in Iran. The study of the Azerbaijani example, may provide insight into the impact of formal language usage in broadcasting media on Tabriz's people. The mother tongue in Tabriz is Azerbaijani, which belongs to the Turkic language family, while the Indo-European language of Persian is their second language (Bani-Shoraka 2009:106; Erfani 2012:10). The Azerbaijani language has been fractured into different dialects, alphabets, and statuses across the countries of Iran, Republic of Azerbaijan, Iraq, Turkey, Syria, Turkmenistan, Uzbekistan, Kazakhstan and Estonia (Ethnologue, 2010). Nevertheless, despite the fact that Azerbaijani language is the main language of some broadcast media, there has been no in-depth investigation of people's attitudes towards their local media channels that use formal languages instead of Azerbaijani.

The remainder of this paper is organized as follows. We next describe the media arrangement in Azerbaijani, especially in Tabriz. This is followed by a review of prior literature. We then describe our research method that involves the analysis of the interviews, synthesis and descriptive statistics. This is followed by the presentation of the main results and its discussion. The last section describes the discussion and conclusion based on the categories that the interviewees mentioned and their attitude towards the television and radio programs.

\section{Literature review}

"We should not be too quick to see the media as all-powerful, and the public as mere puppets of media control. The relationship is not a straightforward one. The reading, listening and viewing public can also choose not to buy, listen or watch; they can switch off, change allegiances and in some cases challenge versions of 
events." (Thornborrow 2004, p. 57-8) Regarding the situation of minority languages and their use in the media, there have been studies demonstrating the usage of language in media based on the language policy of the given country.

Kulyk (2010) suggests that the ideology used in Ukrainian media is centrism despite the fact that both Ukrainian and Russian are used in the Ukraine, the former as the language of the state and the latter as the language of certain social situations. In fact the ideology of centrism marginalizes the other ideologies and considers the population as ideologically homogenous despite differences in culture or language. TV and radio show programs are broadcast in both Ukrainian and Russian without translating either into the other; for example, talk shows, audio or video quotes of speeches. These practices have normalized the acceptance of both languages and a view of Ukrainian society as a bilingual one (Kulyk 2010:87-96).

Since Turkey applied to become a member of the EU (European Union), according to O'Neil (2007) it has had to follow the structures of the EU regarding its Kurdish minority. So in addition to some private courses and publications in Kurdish, the Kurds were allowed radio programs for four hours per week and TV programs for two hours per week (p. 78).

According to Ferrer (2000), the Catalan Council on Culture reveals that the amount of Catalan ${ }^{1}$ used in the media in the years leading up to 2000 showed a considerable increase, and that radio was almost completely in Catalan. However the status of Catalan on TV was weaker than that of Spanish and of the four public channels where half of them were in Catalan, half in Spanish (p. 192)

Kuoega (2008) investigates the use of indigenous languages in Cameroon and the attitudes of undergraduate students to those languages and their ability to use them. The results show that in addition to English and French (the official languages of Cameroon), there are almost 250 indigenous languages (p.86). Kuoega (2008) believes that urbanization endangers minority languages in Cameroon (p.105-7). Some indigenous languages are used on the radio, but none are heard on TV (p. 99101). In Hassanpour's (1992) view, the use of minority languages only in personal

\footnotetext{
${ }^{1}$ Catalan language is spoken with no official recognition in parts of the Spanish autonomous communities.
} 
Asefeh Zeinalabedini

interactions will not make a standardized language and will in fact lead to language extinction. Hassanpour 1992 suggests that one cannot expect a minority language to survive accompanied by mass media, computer games and other means of technology using the dominant language of the country.

Moring et al (2011) find that the choice of language in media depends on government policy towards media. If all the conditions for ethnolinguistic vitality were equal, the minority language audience would have preferred to use media in their own language and not in the majority language (p. 172).

Moring et al's research was conducted across four European regions. Different tests have been performed to measure the amount of media use by young people in the four regions with interesting results. For example, the Finnish study showed that by the time Finnish youth turn 28 years old they are actively using media in both Swedish and Finnish at home. This suggests that "the choice of media language in many ways relates to the identity process; it is not only a consequence of a person's background, but also a vehicle for identity maintenance." (p. 180).

Moring et al (2011) conclude that the minority language speakers in both mono/bilingual families understand the status, demography and the institutional support of the minority language group rather similarly. This is accurate; however, it fails to consider the fact that the preferred media is their mother tongue. Finally, according to the findings in the article media can be an important vehicle in maintaining and supporting the ethnolinguistic vitality, but the viability depends on objective factors such as minority language media content. (p. 184)

Moring et al (2007) shows that in those regions of Finland, where Swedish is predominant, it is used as the language of media, but in places where Finnish is the predominant language and especially in bilingual families, the media's language is Finnish.

As the audience are interested in language use in media, it is appropriate to gain some information about minority languages in Iran and their use in the media as well as Tabriz TV and radio based on the government's language policy in the following studies.

According to Mirvahedi (2012:1) the Iranian constitution includes a law which allows minority language speakers to use their native language whenever needed, 
but in practice there are some complications; that is, poeple are compelled to write in Persian, the official language of the country and not in their native language. In Iran there is no independent private TV or radio channel and local channels are state owned. Iranian Azerbaijanis are Persian-Azerbaijani bilinguals.

Prior studies provide mixed evidence regarding language use in media and people's attitudes towards it in Iran. For example, Mehrton (2008) worked on language policy and planning in Iran with the aim of studying the possibility of applying Spolsky's (2004) framework to the sociolinguistic characteristics of the Iranian situation. As the main result, she found "the development of an insight into the correlation between Iranian language policy and the sociolinguistic setting, as guided by Spolsky (2004)."

In Ardebil', Sepehri (2010) reports that "trust" is the most important factor for people to be attracted and listen to local Ardebil radio channel (p. 244). Sepehri (2010), shows that people in Ardebil do not trust in Ardebil radio and the factors that he refers to show that Ardebil radio programs do not value people's language, ethnicity and culture which makes them ignore and lose their trust in their local radio (p. 250).

Jahani (2005) states the Balochis in Iran do not receive any TV programs in Balochi language, even though they have had daily radio programs on Radio Zahedan since the 1960s. Jahani notes that there have been some improvements to feature Balochi TV programs more regularly since 1979 with different programs related to Balochi culture (dance, songs and lifestyle) on state TV channels (p. 156).

Sheyholislami (2010) focuses on the Kurdish language manifestation on media and internet and states that this language is maintained and considered as the remarkable language of its media to prove the Kurdish identity. He also mentions the difference between satellite television and internet where the former sounds to develop mutual intelligibility among the speakers while the latter seems to expand the language based on the alphabet and regions.

Iran's Media Centre of Research works on the number of media users and their trust towards the programs in local media channels in Gilan province. The local

\footnotetext{
${ }^{2}$ The centre city of other Azerbaijani-speaking province in Iran
} 
language of the people in this province is Gilaki, and their local TV channel is called Baran. As it is shown, in the autumn 2013, out of 400 informants, $74 \%$ are interested in television programs. The reasons of the dissatisfaction of the other $26 \%$ who do not watch TV were as diverse as: lack of time, switch to watching Iran State's channels, satellite channels, no attractive programs and individual incentive, where first three of them were the most important ones and include a higher percentage as 27, 27 and 26 respectively. Following on respondents, Customer Satisfaction Score is as $14 \%$ highly interested.

It should be mentioned that there is either no access to the possible research on the other minority languages in Iran as Luri, Tati and others or there are not much done in this regard. So we mention the Azerbaijani language research afterwards.

There are two studies in Iran's Mdia Centre of Research looking at the attitudes of the people of East Azerbaijan province about the media programs in 1941 and 1945. The first survey shows that $86 \%$ of informants in thirteen cities listened to Tabriz radio while only $28 \%$ of them watch TV programs in 1941 . The latter survey demonstrates an average of $77 \%$ of the people who always listen to radio. Most of the informants could not answer the question about the quality of the performances, translations and information and just answered that: "I don't know, I have no idea and it is good."

Bani-Shoraka (2005b) refers to the effect of mass media, especially satellite and Turkish channels from Turkey on the younger generation's culture in Iran. She also refers to the effect of Turkish channels on promoting the status of Turkey as a neighbor country which pursues modernity as well as preserving its heritage -i.e. religious (Islamic) beliefs -in the eyes of youth (p.148). It is also mentioned that Iranian Azerbaijan's progress in technology and modernity as well as the impact of mass media - satellite channels from Turkey -has changed the youth's attitude towards Azerbaijani language in a positive way (p. 149).

Mirvahedi \& Nasjian (2010) believe that the only institutional support for the Azerbaijani language at present in Tabriz is a local radio station, Radio Tabriz, and TV channel, Sahand but he argues that these do not provide enough support for the language. He shows that the number of programs broadcast in Persian exceeds the number of programs in Azerbaijani and this is surprising since it is a local TV for Azerbaijani speakers (p. 176). He also says that programs for children and teena- 
gers are broadcast in Persian which can have an influence on their mother tongue. Mirvahedi \& Nasjian 2010 also believe that movies and scientific programs, which would be better dubbed into Azerbaijani, are also in Persian (p. 176).

Mirvahedi (2012: p.1) refers to Article 15 of the Iranian Constitution, which states that local languages ought to be allowed alongside Persian in mass media and that the literature of these languages should be taught. According to Mirvahedi (2012) the reasons why the speakers are code-switching can be mentioned as their preference for a particular identity, and switching back and forth between two languages show either a lack of a strong choice or an attempt at impartiality.

Hawes and Mirvahedi (2013) examine the influence of satellite channels from Turkey on Tabrizi children learning the Istanbuli dialect of the Turkish language, while they were learning Persian as a second language. It also reports their attitude towards different TV channels inside and outside the country. The authors believe that TV has the role of educating or teaching a new language to the children; when the prestige of this new language grows, its use will increase. This prestige factor of children learning the minority language has a significant role in their future. Children exposed to the language by daily television programs can decide its future's viability. Mirvahedi refers to how Fishman (1991) considers media an important factor in the future of the languages while he also believes that face-toface communication never takes the place of media. Both television and radio are helpful in exchanging culture, but neither of them can cause language shift on their own (p. 1-4).

The main reason for children's preference of Turkish (Istanbuli) programs rather than Azerbaijani is their higher quality. The children interviewed for this research stated that the reason they choose Turkish programs over Azerbaijani or Persian programs is because they are attractive. They also mentioned that the programs on Iranian or Tabrizi channel(s) are "silly", meaningless and they are not worth watching (Mirvahedi 2012, p. 6). The percentages given for the preference of children for language use show that Persian language programs are preferred by the children, but their reasoning shows that they still think Persian programs alongside with Azerbaijani programs are not worth watching because of poor quality.

Mirvahedi (2012) then gives a few economic reasons why parents think that it is suitable for their children to watch Turkish channels rather than Iranian or Tabrizi 
channels. Turkey gives discounts to university students who are fluent in Istanbuli Turkish, and knowledge of this dialect offers the possibility of a better job in Turkey. He states that being part of the larger Turkic community is another reason for an Azerbaijani speaker to prefer Turkish channels to any of the Iranian ones. If the children as the maintainers of the Azerbaijani language do not find the minority channel programs attractive, they will be more willing to watch the international channels from other countries like Turkey (p. 6).

\section{Methodology}

Two methods were used in this reseach in order to obtain the desired data to answer the research questions. Informal interviews was the main instrument employed, while participant observation was used as a complementary method. Participants were recruited to reflect their attitude towards language use in the local media and daily activities in Tabriz.

In the Azerbaijani society of Iran, the matter of trust is paramount, so people should trust the researcher in order to cooperate with him/her during the interview process. For this purpose, I used "friend of a friend" sampling approach (Milroy and Gordon 2003, Meyerhoff and Schleef 2010) to find the participants, who are willing to cooperate in the data-collection process. This is the method that Milroy and Gordon (2003) used to find the participants in their research in Belfast. This approach was used to recruit the participants whose conversations were recorded with the purpose of interviews in this paper.

Interviews help achieve a broad explanation about the diachronic situation of language use in case the interviewees have been asked about how they used to use media and how they use it now. The interview data gives a good perspective of people's ideas about media use and the programs on Tabriz TV. My data would be useful to find out media use among people in Tabriz plus language use on Tabriz local TV, also it will help examine how people in Tabriz use their native language in their daily communications according to the interviews recorded. It would also be helpful to know how much people use Tabriz local TV and radio, how much it is important for them to use their native language and most important of them all, what their attitude is towards language use on local TV and radio.

It should be clarified here that the options of TV channels for people of Tabriz are as follows: Iran State TV channel, Tabriz local TV channel (Sahand TV), Republic 
of Azerbaijan, and Turkey satellite channels and other satellite channels from almost all over the world. The Iranian channels on TV and radio are not private and they are all under the control of the government of Iran. Even the local TV channels which are broadcast programs for different provinces in the country are running within the framework of the government of Iran and they are not permitted to produce and/or broadcast any program outside of the prescribed framework of the state.

"The first obvious thing researchers on multilingualism need to think about are the language(s) in which the questions will be formulated. Language is the key factor, because it needs message about the interviewer's ethnolinguistic affiliation and educational background, and the formality of the speech event, among other things. These aspects will define the interviewee's understanding of the context of the interview and shape responses in multiple ways." (Codo 2008).

"If researchers want interviewees to speak unconstrained, it is often best to let them choose the language of the interaction." (Codo 2008). So the interviewees were free to choose the language of the interview from Persian or Azerbaijani. The language of all of them was Azerbaijani except in one case which was a Persian.

The questions were divided into four categories including: personal characteristics, language use in daily interactions, media choice (local, state, satellite) and their attitude towards language use on media as well as their native language. The interviews had been descriptively analysed based on the answers of the questions.

Table 1: The questions of the interviews

\begin{tabular}{|c|c|c|c|c|}
\hline \multirow[t]{2}{*}{ 岂 } & \multirow[t]{2}{*}{ 落 } & \multirow[t]{2}{*}{ Question } & \multicolumn{2}{|c|}{$\begin{array}{c}\text { Most Responds } \\
\text { /Answers }\end{array}$} \\
\hline & & & $\stackrel{\text { Dे }}{\circ}$ & 苞 \\
\hline I & 1 & Do you watch television? & $\mathrm{x}$ & \\
\hline & & & $\mathrm{x}$ & \\
\hline & 2 & Do you watch Tabriz local channel, Sahand TV? & $\mathrm{x}$ & \\
\hline & 3 & Do you watch Iran's State TV? & $\mathrm{x}$ & \\
\hline & 4 & Do you watch Satellite TV channels? & $\mathrm{x}$ & \\
\hline
\end{tabular}




\begin{tabular}{|c|c|c|}
\hline \multicolumn{2}{|r|}{5} & Do you watch programs from Republic of Azerbaijan? \\
\hline & 6 & Do you watch programs from Turkey? \\
\hline & 7 & Which programs are you interested in watching on each TV? \\
\hline & 8 & In which language do you watch TV? \\
\hline & 9 & What is your attitude towards language use in Tabriz TV? \\
\hline & 10 & What are the weak and strong points of Tabriz TV? \\
\hline & 11 & $\begin{array}{l}\text { Do the satellite channels have any influence on the } \\
\text { language use in Tabriz? }\end{array}$ \\
\hline II & 12 & What is your attitude towards your daily language? \\
\hline & 13 & Which language do you prefer to use with your children? \\
\hline & 14 & Which language do you use with your parents? \\
\hline & 15 & Which language do you use with your grandparents? \\
\hline & 16 & $\begin{array}{l}\text { As an Azerbaijani, Which language do you usewhen a } \\
\text { Persian speaker is speaking to you in Persian? }\end{array}$ \\
\hline III & 17 & Do you listen to Tabriz radio? \\
\hline & 18 & What is your attitude towards the langauge use in radio? \\
\hline & 19 & Which programs are you interested in radio? \\
\hline IV & 20 & Do you read the newspapers published in Tabriz? \\
\hline & 21 & $\begin{array}{l}\text { Have you read a bilingual (Persian-Azerbaijani) book in } \\
\text { Tabriz? }\end{array}$ \\
\hline & 22 & Is there a clear policy for language use in Tabriz radio and TV? \\
\hline
\end{tabular}

\begin{tabular}{|c|c|} 
& $x$ \\
\hline$x$ & $x$ \\
\hline & $x$ \\
\hline & $x$ \\
\hline & $x$ \\
\hline & $x$ \\
\hline$x$ & $x$ \\
\hline$x$ & \\
\hline$x$ & \\
\hline$x$ & \\
\hline & $x$ \\
\hline & $x$ \\
\hline$x$ & \\
\hline & \\
\hline & $x$ \\
\hline
\end{tabular}

Note: The questions were devided into four categories including: personal details, language use in daily interactions, media choice (local, state, satellite) their attitude towards language use on media as well as their native language

\section{A. Tabriz local TV channel (Sahand) and radio}

The first main category in the data has been recognized as watching Sahand TV. The first question seeks information on if they watch Tabriz TV and listen to Tabriz radio at all and if so, which programs they are interested in. Following the answers, they give different reasons for using and not using TV/radio which will be demonstrated as sub-categories such as: frequency, what programs, reasons, the attitude towards the quality of the programs. It should be clarified here that the options of TV channels for people of Tabriz to watch are as follows: Iran State TV channel, Tabriz local TV channel (Sahand TV), Republic of Azerbaijan, and Turkey satellite channels and other satellite channels from almost all over the world. 
The young people of Tabriz speak Azerbaijani at home and other domains in the city, but they tend to watch state TV in both Azerbaijani and Persian, both the local channel and satellite channels. The youth of Tabriz do not have access to appropriate programs from state TV and Tabriz local TV and radio. Although the educated understand Persian, some of the older generation do not have any knowledge of the language which means they cannot access all the programs on local Tabrizi TV.

Tabriz radio was established in 1945-6 when Tabriz was independent from Iran. Initially, all programs were in Azerbaijani. Tabriz radio switched to Persian after the defeat of the Democratic Party of Azerbaijan in 1946 (Hei'at 2002:263-5). All radio programs were broadcast in Persian until the 1979 Islamic revolution after which Azerbaijanis were allowed to broadcast programs in Azerbaijani from Tabriz radio. The programs from state TV were still broadcast in Persian until recently, when the central government established a local TV channel for every province, including East Azerbaijan, Tabriz. The Tabriz TV channel produces all programs in Tabriz or Tehran, and does not use any programming from the Republic of Azerbaijan.

The answers of the interviwees to the questions will be analysed in the next sections.

\section{A.1 The frequency of watching Sahand TV or listening to the radio}

The interviewes start with a question about the frequency of watching local televiosion and listening to local radio. The first interviewee' ${ }^{3}$ answer to the first question is as "on the whole, no (I'm not watching TV or listening to the radio)", then she states that she was watching TV for a time period in the past and finally she changes it to "recently, last month (I was watching...)." Out of the 22 interviewees, most of them make it difficult to determine if they do not watch Tabriz TV and do not listen to the radio at all; only four of them directly state that they like it, so they use it.

Faezeh, a 63 years old retired teacher, states that she watches TV every night and listens to the radio in the daytime when she is working in the kitchen. Zohre is a

\footnotetext{
${ }^{3}$ The personal details of the interviewees are presented in table (2).
} 
nurse working in a hospital the entire day. She remarks that she is not willing to watch TV and also: "it would be more interesting if we had a real local TV at least to reflect the news and information related to the geographical land. I'd like to watch [East Azerbaijan] province's news, but I don't get anything from that; it's all cliché." Other reviewers did not have more interest to watch local TV or listen to its radio.

Some of them discussed that watching television is not used in a way that one could get the best possible benefits from it. For example, Mahvash does not listen to the radio, but she sometimes watches comedy programs on Tabriz TV. She does not watch her favourite comedy program anymore because, according to her, the decoration of TV studio is not modern enough.

On the other hand, some interviewers use TV and Radio to gain specific information about local weather forecasts, weather information, events, news or an entertainment tool. Ali and Mehran state that it is mostly Taxi drivers, villagers, elders and families of students who watch local TV or listen to the radio. They believe that these groups all like watching TV because of the reasons as follows: The drivers are driving almost all day, so they listen to the radio or gain information about the condition of the roads, or to avoid feeling bored and as well they watch TV, especially news program. The villagers usually watch their special program, if they have the related facility, to have access to the newly updated information about farmers and planting and so on. Elders are also interested in watching different programs to be entertained and finally families are interested to gain information about the events in the city, especially in the winter to make sure about the weather, if the schools close the day after because of the heavy snow.

\section{A.2. Favorite programs of viewers and listeners}

Although most of the informants mention that some of the local media programs did not meet their expectations, they refer to the programs that are interesting to watch or listen and try to explain them. Moreover, they mention the possible methods to improve the quality of the programs, so that they become more interesting and attractive for the addressee(s). The most popular program amongst Tabrizi interviewed people were Azerbaijani news at $11 \mathrm{pm}$. They would like to stay updated about the latest events and news in their province and city; however, they explain what the deficiencies of the news program are in Azerbaijani 
language. Sanam used to watch $11 \mathrm{pm}$ News program and a problem solving, social program" and enjoyed it, but she states that she does not have time anymore to follow the program since her working hours have been changed and she is so busy.

Sanaz, a housewife, and Sahar, a primary school teacher, are mostly watching TV series and villagers' programs in which the Azerbaijani language is used as a daily language of people. Mehran and Ruhi are interested in the comedies from Tabriz local TV, but they do not find anything interesting in other programs. Ruhi states: "If we had attractive programs, we'd like to watch our own programs."

The following would refer to the reasons of the interviewees for not watching local TV or listening to the radio.

\section{A.3. The reasons for not watching TV or listening to the radio}

\section{Accent of TV speakers}

Most of the interviewees refer to the strange accent of the speakers on radio and TV generally. This is the main reason why they are not interested in watching TV and listening to the radio. According to Doerfer (1998:273) "...The dialect of Tabriz...enjoys...wide recognition as a standard language in Iranian Azerbaijan, although it has never developed into an official written language”. Sanam explains that "the accent used is not interesting for me. I like the colloquial accent people use in Tabriz, but the Radio uses a very formal one which I do not enjoy. It is so pretentious, I think. It's not my type." Then she continues: "For example, I really enjoy my friend's accent. For example, her husband is from Naghadeh or Takab (cities in West Azerbaijan) or somewhere around there, they have a special accent, but they don't use Persian when they talk. And rarely when they can't find a Turkish word for something, they use a Persian word for it; it's not at all pretentious and I really enjoy that. I try to be as they are and use the Turkish words and not the Persian ones, and I try to edit myself not to use pretentious Farsi words." She then adds that: "For example, they try to speak formally in the news and according to the [Azerbaijani] grammar, but they cannot rely to imitate it."

Ali, one of the informants, who has already worked on the diversity of dialects in different Azerbaijani cities in northwest of Iran, believes that: "Just imagine that they choose a very inferior accent in Tabriz. You know that there are different 
accents in different places in Tabriz. They choose the most inferior one and try to promote it as our source and main accent." He continues that: "By inferior accent I mean a non-dominant one. In this accent the number of speakers is limited. You cannot find this in any part of our literature... It [the accent] is also not following the phonological rules in Azerbaijani and is breaking those rules." Faezeh mentions a similar idea: "[the people who are speaking in the plays and TV programs] are uneducated people; they do not have enough knowledge. The words that they use are so low-level that they are not even used in the city. It is like they have specially talked to the countryside, not cities."

Savalan is a guest in one of the TV programs as an Azerbaijani expert specializing in literature. He is watching TV programs and listening to Tabriz radio, but his view about the language used on TV and radio is that: "Consider that the language in Tabriz TV and radio is not even Tabriz's colloquial languages or that we can say our elders are speaking like this in the streets or in the shops and other places. It's not like that at all. Generally, it's either their public program or literature; the words which are used in all of them, all the sentences are mostly Persian words. And also the fact is that we should talk as if for example a peasant in the villages of Qaradaq (a place in the East Azerbaijani province around Tabriz) or a farmer can easily understand everything. They want to hear that, for example these days there is a disease among the cows, and an expert is trying to explain it and make it clear to what to do about it. He explains it in a way that the miserable villager does not understand anything about it. ... Because of that, the language on Tabriz TV and radio is not colloquial or [related to the] literature.... The expert is using difficult scientific words to show his [social] position, so the result would not be socially and culturally positive and it is damaging both Persian and Azerbaijani languages."

Mahvash also mentions the quality of the programs and that they are not interesting enough. She continues: "You think you're listening to a Turkish program, when I listened to the programs, the number of the Persian and Arabic words which are used are dominant [in the Turkish words]." She adds: "There is no creation; their creativity is that they speak more Persian. This is their creativity. They look at Amu Purangh's program (children's program on Tehran TV channel) and make a children's program. The speaker comes in with a colorful dress speaking Persian with a strong Persian accent with children. Half of them understand [the language of the speaker], half don't. They are selective, yet it is clear the children were brought there." 
Zohre is referring to the grammatical mistakes in Tabriz TV news program and declares that: "The language which is used in TV is full of grammatical mistakes, especially that it starts with Persian words and everybody feels that it will continue in Persian, but it ends with an Azerbaijani verb." While the language used in TV is originally Azerbaijani in her idea and she does not have any difficulty understanding, it is in fact quite old and even sometimes difficult for the young generation to understand. She says: "Of course they use some strange Persian words in between these strong Turkish words which is nice and understandable for me as an old person, but they sometimes add a Persian word which is not even common to use, then it is meaningless. But even in their news, the words which are used are not common."

\section{Lack of creativity and new information}

Some of the interviewees speak about how the programs on Tabriz TV or radio are not modern and do not include new topics to talk about. For example, Sanam and Mahvash refer to the lack of interesting topics on the programs on both Tabriz TV and radio. Mahvash also mentions that: "Radio and TV are not up to date at all. For example, there are quite decent, new pop music singers in Tabriz recently. They do not play their songs on TV and radio, instead they play [traditional] Ashiq songs which were produced along time ago and it's not even new, maybe it is from the archives before the revolution. Or they play Persian music."

Faezeh expresses her ideas in a similar way when she mentions that some topics are repeated all the time and they are not even funny enough to laugh at. She believes that the language used in TV is originally Turkish which makes it difficult to understand for the young generation because they have not learnt those words before.

\section{Critical perspectives towards Azerbaijani language use in media}

In line with the critical tendencies, it should also be pointed out that the topic of minority languages, especially Azerbaijani, has always been controversial in Iran. Hence "Official Iranian sources tend to deflate the number of Azerbaijanis in order to project a clear Persian majority in Iran, and thus preserve their claim to linguistic and cultural predominance." (Shaffer 2002:222). Tabriz, as the center of Azerbaijani-Persian contact, creates a complex linguistic situation in the city 
(Erfani, 2012:10). Examples of contact can be found in different domains of both private sectors, which involves people's daily lives and private businesses, and public sector, which operates under the supervision of the government in the local TV/radio.

It is not only linguistic, ethnic and cultural differences which affect mutual relationships between people and government, but also there are economic and political inequalities which create some obstacles for the linguistic stuctures.

Based on the interviews, there are two different perceptions about the use of Azerbaijani language in media. Some of the interviwees, such as Savalan who is a historian in Azerbaijani literature believe that the language used in media depends on the media authorities to choose. On the other hand, others such as Ali, think that it is a linguistic pattern decided by special policies in this area. This matter is consistant with numerous studies that highlight the effects of the political attitudes on langauge use in media (Aarts and Semetko 2003; Robinson and Sheehan 1983).

Television programs are considered effective- based on the type of programswhile some reseachers argue that entairtning aspect of TV programs might be highly promoted which cause undermining the informative side. On the other hand, the more entertaining programs may lead to the politically ignorant audience (Vreese 2004 ${ }^{4}$; Postman 1985).

\section{Satellite channels (Turkey and the Republic of Azerbaijan)}

People in this area have access to satellite media. They mostly watch news, music, social and cultural programs from Turkey and Republic of Azerbaijan. Almost all the interviewees watch satellite TV channels from the Republic of Azerbaijan and Turkey. Most of them, including Majid, Sanam, Elham, Ali and others are willing to watch the music competition from Khazar TV, Baku, in which young traditional Azerbaijani singers sing professional songs, and the judges choose the winner. People express their feeling towards this program more than other programs as they say that it makes them happy. Their second preference is the "Sayyah" which demonstrates Azerbaijani traditions in Baku's villages as well as Ayzaur who is travelling to different parts of the country with the emphasis on wedding ceremonies.

\footnotetext{
${ }^{4}$ The Azerbaijani language used in Tabriz local TV and radio programs is full of Persian words. The local media points to words from similar lexical fields borrowed into Persian.
} 
Elham and Majid state that local programs are not informative enough, so they are gaining some of their required information from satellite channels.

Some of the respondents even go as far and watch only Turkish language channels. As Mohammad says, “One of our relative's kids always watches Turkish TV channels, but nothing from Persian channels, now that she is going to the school she has a problem understanding Persian language." Similarly in Mirvahedi's 2012 study, children who were interviewed for his research stated that they chose Turkish programs over Azerbaijani or Persian programs because they are attractive. They also mentioned that the programs on Iranian or Tabrizi channel(s) are "silly", meaningless and they are not worth watching (Mirvahedi 2012).

\section{Attitudes towards Azerbaijani language in Tabriz and Persian influence on it}

The informants were asked about their attitudes towards the daily Azerbaijani language of Tabrizis. Most of them, particularly the educated, believe that the Azerbaijani language used in Tabriz includes Persian as well, but it is different from what is used in the local media. ${ }^{5}$ The following ideas will shed light on how different Azerbaijani language is used in both media and daily life.

For example, Sanam describes her idea as follows: "I like the way that normal people speak Farsi, but not the formal one that the Radio uses, I mean the Turkish mixed with Farsi. The people usually speak Turkish. By the way, not all the words that we use in our everyday speech are Turkish, maybe $80 \%$. And then when they use words of other languages [like Persian, instead of Azerbaijani], it's because of the weakness of the educational system that we don't know certain words. And many other people who are from towns and villages don't know the words properly. For example, for the word Tomato, they use Goje (Persian) and not Bamador (Az.)." From Fazehe's point of view, the words Tabrizi people use are all in Azerbaijani with the difference that since the educational system was and is in Persian, there are normally influences on the daily Azerbaijani language.

More or less participants believe that the Azerbaijani used in the daily life of Tabrizi people includes more Azerbaijani, but less Persian. Ali states that: "There are books I can show you in which the education ministry [of Pahlavid dynasty, 
Reza Shah] named Mohammad Ali Forughi, followed by Persian literature expert Iraj Afshar, recommended that the Shah's government keeps the children of Ahar [a close small city near Tabriz] in 24 hours institutions, certainly with Persian teachers, and without permission to go back to their families. Then [it is expected that] in 30 years not only their accent, but also their language will change into Persian.”(For further information please refer to Hei'at 2001).

The educational system also has great influence on native language use. The medium of instruction is Persian and students generally start learning Persian from 6-7 years of age. There is a hypothesis which clarifies that mismatch between the language of the home and the language of the school results in academic delay (Downing, 1974; UNESCO, 1953). The exemplification of the "linguistic mismatch" hypothesis is mentioned in the UNESCO statement as: "it is axiomatic that the best medium for teaching a child is his mother tongue" (UNESCO 1953, p. 11).

Referring to the educational method, Sanam believes that it is a weakness that Tabrizi children cannot learn their native language in school, instead learn the official language of the country. She thinks that in this way the original words of Azerbaijani will be forgotten during the next years. But Sahar has a different idea. She is a teacher in a primary school in south of Tabriz. She describes that teachers have to talk in Azerbaijani in school because the kids are from families who are always watching satellite from Turkey; they more or less understand Persian, but cannot speak. She states that school authorities speak to the families of students to encorage them to watch Persian channels from state TV as well, so that they increase their Persian comprehension level because they will confront it a lot in the future in their life.

\section{Discussion and Conclusion}

The main focus of this study was the investigation of the society's linguistic attitude to use of the local media broadcasting. One of the research findings show the effect of the official language on the native language in people's attitudes towards using their native language in the broadcast media. The findings are interpreted as the local television and radio are to promote the development of the official language instead of the native/local language. Other results also reveal that the language used in broadcasting local media is not the appropriate version of Azerbaijani, but moves towards more Persian than Azerbaijani. 
In view of the findings, it should be pointed out that there is a mismatch between the language of educational system and the home language (Cummins, 1992). Media language also brings out another issue for the younger generation in trying to have a positive and useful connection with the media. This big linguistic gap makes it even harder for the people to find out about their identity.

Other findings show that language use in Tabriz media is so different from the language which is spoken in the daily life of Tabrizians. This means there is a lack of any perceived logical link between the language used in media programs and the audiences' interests or even the lack of any great desire to listen to Azerbijani tones.

The perspective of people about the accent used in Tabriz media is an evidence that people in Tabriz are watching "Sahand" TV and listening to the radio, so that is a reason they can cite all aspects of this media. It is suggesting that the attitude of the media viewers and listeners towards language use stem from the speech linguistic patterns used in different programs. As such, the specific types of linguistic pattern in any type of mass media will influence the level of interest of the media users in the programs.

This result is consistent with a research from Iran's Media Research Centre (1979), arguing that the realities are not reflected in TV programs, because of a censorship, conflict news and lack of critical media literacy. It is also suggested that Media broadcasting needs programs which increase the awareness of people as well as providing them with entertaining programs. We also find out that people's attitudes towards their local media is more or less the same in 1979 or 2011 . This might show that there is not enough contact between the people of Tabriz and their local media.

\section{Acknowledgments}

I would like to thank Prof. Peter Hill for his comments and suggestions as well as all the other professors who have taught me about applied linguistics as an interdisciplinary field of study over the past two years in the Australian National University. 


\section{References and notes:}

Aarts K. and H. A. Semetko .2003. The Divided Electorate: Media Use and Political Involvement, The journal of politics. 65(3), 759-784.

Bani-Shoraka, H. 2005. The Iranian Language Policy of the Twentieth Century. In: Annika Rabo and Bo Utas (eds.): The Role of the State in West Asia. Istanbul: Swedish Research Institute. 14:141-50.

Cummins, J. 1992. Bilingual education and English immersion: the Ramirez Report in theoretical perspective. In Bilingual Research Journal, 16(1\&2), 91-104.

Codo, E. 2008. Interviews and Questionnaires". In: Li Wei and M.G.Moyer (eds.): The Blackwell guide to research methods in bilingualism and multilingualism. Malden: Blackwell Publishing Ltd. 158-76.

Doerfer, G. 1998. Turkic Languages of Iran". In: Johanson, L. and CsatE. (eds.): The Turkic Languages. London and NewYork: Routledge. 273-82.

Downing, J. Bilingualism and learning to read. The Irish Journal of Education, 1974, 8, 77 88.

Edwards, J. 2009. Language and identity: An introduction. New York: Cambridge University Press.

Erfani, P. 2012. "Azeri morphosyntax: The influence of Persian on a Turkic language", MA: Simon Fraser University.

Ethnologue: Languages of the World. 2010. Resources about Azerbaijani language Available in $\measuredangle t t p: / / w w w . e t h n o l o g u e . c o m / l a n g u a g e / a z b>$

Ferrer, F. 2000. "Languages, Minorities and Education in Spain: The Case of Catalonia". Comparative Education 36 (2). Special N.22: Nigel Grant Festschrift. Taylor and Francis Ltd. 187-97.

Fishman, J. 1989. "Language and ethnicity in minority sociolinguistic perspective". Clevedon: Multilingual Matters Ltd.

Fishman, J. 1991. "Reversing Language Shift: Their etical and empirical foundations of assistance to threatened languages". Clevedon, Philadelphia, Adelaide: Multilingual Matters LTD.

Hartley, J. 2004. "Television, nation, and indigenous media. Television \& New Media". 5, $7-25$.

Hassanpour, A. 1992. "Nationalism and Language in Kurdistan 1918-1985". SanFrancisco: Mellen Research University Press.

Hawes T \& S.H. Mirvahedi. 2013. "Language attrition and loss of identity: Azeri-Farsi Code- switching in Tabriz, Iran". In K. U. Ihemere (Ed.), Language contact: A multidimensional perspective. 248-265. Cambridge: Cambridge Scholars.

Hei'at, J. 2001. "A survey in the History of Turkish Language and Dialects Tehran". Tehran: Peykan publications. 
Holems, J. 1992. "An Introduction to Sociolinguistics". London and NewYork: Longman.

Jahani, C. 2005. "State Control and its Impact on Language in Balochistan". In: Annika Rabo and Bo Utas (eds.): The Role of the State in West Asia Istanbul: Swedish Research Institute. 14:151-63.

Jones, E. 2007. "The Territory of Television: S4C and the Representation of the "Whole of Wales'". In M. Cormack \& N. Hourigan (Eds.), Minority language media: Concepts, critiques and case studies. Bristol: Multilingual Matters.

Joseph, J. E. 2004. "Language and identity: National, ethnic, religious". New York: Palgrave Macmillan.

Kouega, J. 2008. 'Minority language use in Cameroon and educated indigenes' attitude to their languages". International Journal of the Sociology of Language. 189: 85-113.

Kulyk, V. 2010. "Ideologies of language use in post-Soviet Ukrainian media". International Journal of the Sociology of Language. 2010: 79-104.

Lysaght, R. 2009. "Language image in national minority language television idents". TG4 (Teilifi'snaGaeilge, Ireland) and Whakaata Maori (Maori Television, New Zealand). EstudiosIrlandeses, 445-57.

Madianou, M. 2005. "Mediating the nation: News, audiences and the politics of identity". London: UCL Press.

Mehrton. A. 2008. An Honors thesis: "Investigating Iran: A challenge for language policy". The Australian National University. Australia, Canberra.

Milroy, L. \& M. Gordon. 2003. "Sociolinguistics". Malden: Blackwell.

Mirvahedi, S.H. 2012. "The Role of satellite Channels in Language Shift/Maintenance: The Case of Tabriz, Iran”. Proceedings of FEL XIV, 36-41. Auckland: Foundation for Endangered Languages.

Mirvahedi, S.H. and Nima Nasjian, 2010. "Is Azeri going to live or leave?" in HywelGlyn Lewis and Nicholas Ostler (eds): Reversing Language Shift: How to Re-awaken a Language Tradition, Proceedings of the Four tenth FEL Conference, Carmarthen, Wales, 175-180.

Moring et al. 2011. "Media use and ethnolinguistic vitality in bilingual communitis". Journal of Mulitilingual and Muticultural Development. 32 (2) 169-186.

Moring, T. and Ch. Husband. 2007. "The contribution of Swedish-language media in Finland to linguistic vitality". International Journal of the Sociology of Language. 187-88:75- 101.

O'Neil, M.L. 2007. "Linguistic Human Rights and the Rights of Kurds". In: Zehra F. Kabasakal Arat: Human Rights in Turkey. Philadelphia: University of Pennsylvania Press. 72-86.

Research centre of Islamic Republic of Iran's Television and Radio. 1941, 1945, 1959 and 1979, the foundation of research. Tehran, Iran.

Robinson, Michael J., and Margaret Sheehan. 1983. over the Wire and on TV. New York: Russell Sage Foundation. 
Romaine, S. 1995. "Bilingualism”. Second Edition. Univeristy of Oxford: Blackwell publishers.

Schleef, E. and M. Meyerhoff. 2010. "Sociolinguistic Methods for Data Collection and Interpretation". The Routledge Sociolinguistic Reader. 1-26.

Sepehri, M.B. 2010. "Local Radio Audiences in Iran: An Analysis of Ardebilian People's Trust and Satisfaction with 'Sabalan' Radio". Broadcast Education Association. Journal of Radio and Audio Media. 17(2)236-250.

Shaffer, B. 2000. "The Formation of Azerbaijani Collective Identity in Iran". Nationalities Papers. 3(28)449-77.

Sherrington, R. 1975. Television and language skills. London: Oxford University press.

Sheyholislami Jaffer. 2010. Identity, language, and new media: the Kurdish case, Lang Policy, 9: 289-312.

Thornborrow, J. 2004. Language and the media. In Language, Society and Power: An Introduction. London and NewYork: Routledge. 57-8.

UNESCO. 1953. The use of vernacular languages in education. Monographs on fundamental education, The United Nations Educational, Scientific and Cultural Organization.

Vreese de Claes H. 2004. The Effects of Frames in Political Television News on Issue Interpretation and Frame Salience Journalism \& Mass Communication Quarterly. 81(1) 36-52.

Weisse, H. G. 1985. Teaching foreign language in the Federal Republic and Germany. In R. L. Hilliard (ED), Television and adult education, Massachusetts: Schenkmen Book Inc. 


\title{
SUMMARY
}

\section{The People's Attitude towards the Language Use in the Local Media Broadcasting, A Case Study: Azerbaijan, Tabriz}

\section{Asefeh Zeinalabedini}

\author{
Australian National University, Australia
}

This paper aims to describe the barriers of the language development with investigating the influence of an official language on native language that is used in broadcasting media, including television and radio. The data for this study is generated from a local televisionin Tabriz, informal and friendly interviews and communications with audiences. Data analysis is informed by a critical discourse analytic approach. Research's findings about people's attitude towards using their native language in the broadcast media suggest that a significat effect of the official language on the native language. The findings are interpreted as the local television and radio are to promote the development of the official language instead of the native/local language. Other results also reveal that the language used in broadcasting local media is not the appropriate version of Azerbaijani, but moves towards more Persian than Azerbaijani.

Keywords: Media, official language, Azerbaijani language, people's attitude

Appendix 1. A summary of personal details about interviewees

\begin{tabular}{|l|l|l|l|l|l|l|c|}
\hline & & & & & & & \\
\end{tabular}




\begin{tabular}{|c|c|c|c|c|c|c|c|}
\hline Faezeh & 60sf & Diploma & Retiredteacher & Az. & Tabriz/Ahar & Az. & $\mathrm{S}$ \\
\hline Mehran & $60 \mathrm{sm}$ & Bachelor of arts & Retiredteacher & Az. & Tabriz & Az. & $\mathrm{M}$ \\
\hline Ruhangiz & $60 \mathrm{sf}$ & Teaching diploma & Retiredteacher & Az. & Tabriz & Az. & $\mathrm{M}$ \\
\hline Ali & $50 \mathrm{sm}$ & Engineerin $\mathrm{g}$ & $\begin{array}{l}\text { University-teacher } \\
\text { and engineer }\end{array}$ & Az. & Tabriz/Sarab & Az. & $\mathrm{S}$ \\
\hline Fatemeh & $40 \mathrm{sf}$ & Diploma & Shopseller & Az. & Tabriz & Az. & $\mathrm{M}$ \\
\hline Sanaz & $30 \mathrm{sf}$ & Diploma & Housewife & Az. & $\begin{array}{l}\text { Tabriz/ } \\
\text { Meshkinshahr }\end{array}$ & Az. & $\mathrm{M}$ \\
\hline Sahar & $30 s f$ & Diploma & Teacher & Az. & $\begin{array}{l}\text { Tabriz/Avillage } \\
\text { near Tabriz }\end{array}$ & Az. & M \\
\hline Asyie & $40 \mathrm{sf}$ & Diploma & Housewife & Az. & $\begin{array}{l}\text { Tabriz/avillage } \\
\text { near Tabriz }\end{array}$ & Az. & M \\
\hline Savalan & $40 \mathrm{sm}$ & Bachelor & Teacher/ TVexpert & Az. & Tabriz & Az. & $\mathrm{M}$ \\
\hline Zohre & 30sf & Medical science & Nurse & Az. & Tabriz & Az. & $\mathrm{M}$ \\
\hline Hamid & $50 \mathrm{sm}$ & Diploma & Watchseller & Az. & Tabriz & Az. & $\mathrm{M}$ \\
\hline Pari & 70sf & Diploma & $\begin{array}{l}\text { Retiredschool- } \\
\text { principle }\end{array}$ & Az. & Tabriz & Az. & M \\
\hline Hamed & $70 \mathrm{sm}$ & Diploma & Retiredteacher & Az. & Tabriz & Az. & $\mathrm{M}$ \\
\hline Hadi & $30 \mathrm{sm}$ & Bachelor in Geography & employee & Az. & Tabriz & Az. & $\mathrm{S}$ \\
\hline Babak & $40 \mathrm{sm}$ & Less than diploma & Owneroftheshop & Az. & Tabriz & Az. & $\mathrm{M}$ \\
\hline Taymaz & $60 \mathrm{sm}$ & - & TVretiredemployee & Az. & Tabriz & $\operatorname{Pr}$ & $\mathrm{M}$ \\
\hline Mohammad & $30 \mathrm{sm}$ & Bachelor in Economics & Employee & Az. & Tabriz & Az. & $\bar{M}$ \\
\hline Nafiseh & $30 \mathrm{sf}$ & Bachelor inAccounting & Teacher & Az. & $\begin{array}{l}\text { Meshkin- } \\
\text { shahr/Tabriz/Teh } \\
\text { ran }\end{array}$ & Az./Pr. & M \\
\hline
\end{tabular}

\section{Note:}

Az. and Pr. has been used for Azerbaijani and Perisan, respectively.

F/M has been used for female/male.

$\mathrm{S} / \mathrm{M}$ has been used for married status

Note that the names of the participants are pseudo-names. 